\title{
Obstetric outcome of teenage pregnancies in a tertiary care centre in Mangalore, Karnataka, India
}

\author{
Anusha Emani ${ }^{1}$, Shraddha Shetty K. ${ }^{2 *}$
}

\begin{abstract}
${ }^{1}$ Department of Obstetrics and Gynecology, Gandhi Medical College, Secunderabad, Telangana, India
${ }^{2}$ Department of Obstetrics and Gynecology, Kasturba Medical College, Mangaluru, Karnataka, India
\end{abstract}

Received: 15 February 2018

Accepted: 27 March 2018

\section{*Correspondence:}

Dr. Shraddha Shetty K,

E-mail: shraddha_k1@rediffmail.com

Copyright: (c) the author(s), publisher and licensee Medip Academy. This is an open-access article distributed under the terms of the Creative Commons Attribution Non-Commercial License, which permits unrestricted non-commercial use, distribution, and reproduction in any medium, provided the original work is properly cited.

\begin{abstract}
Background: Teenage pregnancy is a social problem affecting maternal and child health. In India, teenage pregnancy is an important public-health problem, although the national policy of the Government of India advocates the minimum legal age of marriage for girls to be 18 years. The aim of the present study was to observe the obstetric outcome in Teenage pregnancies

Methods: A retrospective analysis of all Teenage pregnancies was done over a period of 1 year from August 2014 to July 2015. Case sheets of all teenage mothers delivered during that period were retrieved. Maternal and neonatal outcome were analyzed and compared with pregnant women $\geq 20$ years of age.

Results: 5859 deliveries occurred during the study period, teenage deliveries were 457.The prevalence of teenage deliveries was $7.8 \%$. Cesarean delivery rate was $56 \%$ vs $42 \%$ (p value $<0.05$ ) among teenagers compared to non teenage pregnant mothers. Preterm delivery rate was higher in teenagers $24 \%$ vs $14 \%$ (p<0.05). 39(8.6\%) teenage mothers had developed hypertension in pregnancy and 42(8.3\%) among non-teenagers ( $\mathrm{p}>0.05)$. Teenage mothers had increased Low birth weight rates $24 \%$ vs $10 \%$ ( $\mathrm{p}<0.05)$.

Conclusions: Teenage pregnancies has a negative impact on maternal and perinatal health. Hence strict laws should be enforced to prohibit teenage marriages. Adolescent girls should be educated about safe sex practices, contraception and complications of teenage pregnancies on maternal and child health.
\end{abstract}

Keywords: Hypertension in pregnancy, Low birth weight, Maternal health, Preterm birth, Teenage pregnancies

\section{INTRODUCTION}

Teenage pregnancy, a social problem, has serious implications on maternal and child health, especially in the context of developing countries. In India, teenage pregnancy is an important public-health problem, although the national policy of the Government of India advocates the minimum legal age of marriage for girls to be 18 years.

Data of the National Family Health Survey (NFHS)-3 revealed that $16 \%$ of women, aged 15-19 years, have already started child bearing. ${ }^{1}$ About 16 million girls aged
15-19 years give birth every year-roughly $11 \%$ of all births worldwide. Complications linked to pregnancy and childbirth are the second cause of death for 15-19-yearold girls globally. ${ }^{2}$

Poor nutrition and early child bearing expose young women to serious health risks during pregnancy and childbirth, like damage to the reproductive tract, pregnancy related complications, such as anemia, pregnancy induced hypertension, preterm labor, cephalopelvic disproportion, maternal mortality, perinatal and neonatal mortality, and low birth weight. ${ }^{3,4}$ 
The factors contributing to the raise in teenage pregnancy rates in developed countries are the declining age at menarche, initiation of first sexual activity at a much younger age and the low rate of contraception usage, while in developing countries, a declining trend is notice. The principle object of the present study was to observe the obstetric outcome in teenage pregnancies.

\section{METHODS}

This is a retrospective analysis conducted of all teenage mothers delivered at Lady Goschen Hospital, a teaching hospital and a tertiary care center located in Mangalore, Dakshina Kannada district. Data was obtained from case sheets, labor records and operation registers of the hospital.

Teenage pregnancy is defined as pregnancy attained between 13-19 years of age. ${ }^{5}$ In the present study, 457 Teenage mothers between the age groups of 17 to 19 years were taken as cases as there were no teenage pregnancies between 13 and 16 years.

Most of the teenage mothers among the cases were primipara, only primipara were taken in both cases and controls to avoid inequality among the two groups. 500 women $\geq 20$ years were taken as controls.

\section{Exclusion criteria}

- Teenage mothers with Chronic hypertension

- Overt diabetes mellitus

- Epilepsy

- Thyroid disease

- Renal disease

- Liver disease

Maternal demographic details like age, educational status, occupation, complications during pregnancy, mode of delivery and baby details were retrieved from the case sheets of all the teenage mothers delivered during the study period.

Maternal and neonatal outcome of cases were analyzed and compared with control groups who had delivered during the same period.

Preeclampsia (defined as BP $>140 / 90$ on two occasions 4-6 weeks apart after 20 weeks of gestation, associated with proteinuria), Preterm delivery (delivery before 37 weeks of gestation) and Cesarean section rates. Prematurity, Low birth weight (baby weight less than 2500 grams)

\section{Statistical analysis}

Chi-square test was used for data analysis; P value of less than 0.05 was taken as statistically significant. Software package SPSS 17 used. variables.

\section{RESULTS}

A total of 5859 deliveries occurred in the study period of that,457 women had teenage pregnancies (Figure 1). The prevalence of teenage pregnancy in the study period was $7.8 \%(\mathrm{n}=457)$.

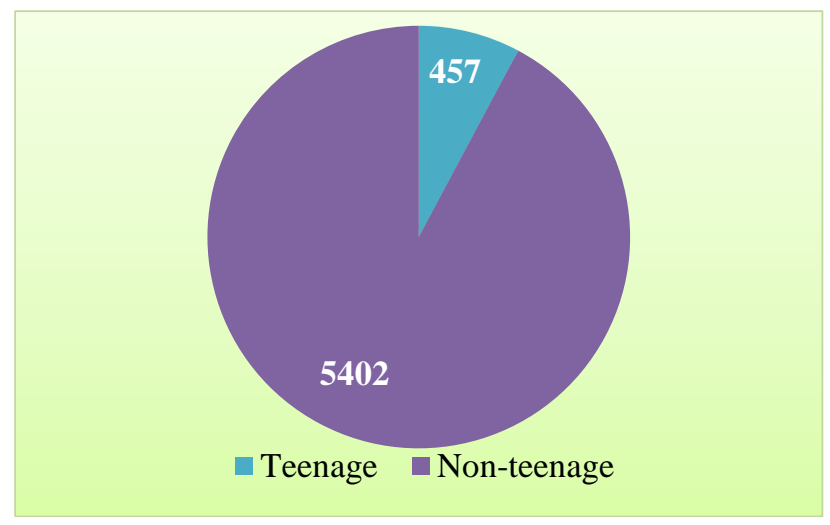

Figure 1: Teenage versus non-teenage pregnancies.

500 non-teenage mothers were compared with the cases. 2 $01(44 \%)$ of teenage mothers had a normal vaginal delivery and $290(58 \%)$ of non-teenage women had delivered vaginally. $256(56 \%)$ among 457 teenagers delivered through cesarean delivery and 210 (42\%) among 500 non-teenagers delivered through cesarean delivery and $\mathrm{p}$ value $(<0.05)$ was found to be statistically significant.

These observations suggest that Cesarean delivery rates are more with teenage pregnancies (Figure 2, Table1).

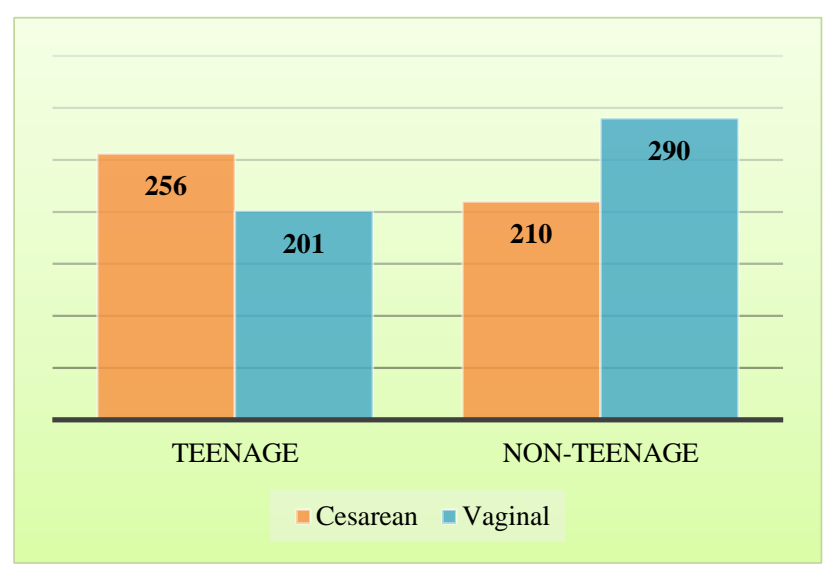

Figure 2: Cesarean rates among teenage and nonteenage groups.

Indications for cesarean section in the study group was Cephalopelvic disproportion $(44.1 \%)$, fetal distress $(26.2 \%)$, breech presentation $(11.3 \%)$ failed induction $(10.1 \%))$ and failure to progress $(8.2 \%)$ (Table 2).

Teenage pregnancies were complicated by Cesarean $256(56 \%)$, 
Table 1: Obstetric outcome in teenage pregnancy vs non-teenage pregnancy.

\begin{tabular}{|c|c|c|c|}
\hline $\begin{array}{l}\text { Outcome } \\
\text { measure }\end{array}$ & $\begin{array}{l}\text { Teenage } \\
\text { group \% (n) }\end{array}$ & $\begin{array}{l}\text { Non-teenage } \\
\text { group \% (n) }\end{array}$ & $\begin{array}{l}P \\
\text { value }\end{array}$ \\
\hline Cesarean rate & $56(256)$ & $42(210)$ & $<0.05^{*}$ \\
\hline $\begin{array}{l}\text { Pre-term } \\
\text { delivery rate }\end{array}$ & $24(110)$ & $14(70)$ & $<0.05^{*}$ \\
\hline $\begin{array}{l}\text { Low birth } \\
\text { weight }\end{array}$ & $24(112)$ & $10(50)$ & $<0.05^{*}$ \\
\hline Pre-eclampsia & $8.6(39)$ & $8.3(42)$ & $\begin{array}{l}0.94 \\
(>0.05)\end{array}$ \\
\hline
\end{tabular}

Table 2: Indications for Cesarean section.

\begin{tabular}{|lll|}
\hline Indications & $\begin{array}{l}\text { Case } \\
(\mathrm{n}=256)\end{array}$ & $\begin{array}{l}\text { Control } \\
(\mathrm{n}=210)\end{array}$ \\
\hline $\begin{array}{l}\text { Cephalopelvic disproportion } \\
\text { (CPD) }\end{array}$ & $113(44.1 \%)$ & $87(41.4 \%)$ \\
\hline Fetal distress & $67(26.2 \%)$ & $41(19.5 \%)$ \\
\hline Breech presentation & $29(11.3 \%)$ & $25(11.9 \%)$ \\
\hline Failed induction & $26(10.1 \%)$ & $34(16.2 \%)$ \\
\hline Failure to progress & $21(8.2 \%)$ & $23(10.9 \%)$ \\
\hline
\end{tabular}

Preeclampsia in 39(8.6\%), Preterm deliveries 110(24\%), and low birth weight babies $112(24 \%)$. In the present study, $110(24 \%)$ of the teenagers had preterm deliveries and $70(14 \%)$ non-teenagers had preterm deliveries and was found to be statistically significant $(\mathrm{p}<0.05)$ (Figure $3)$.

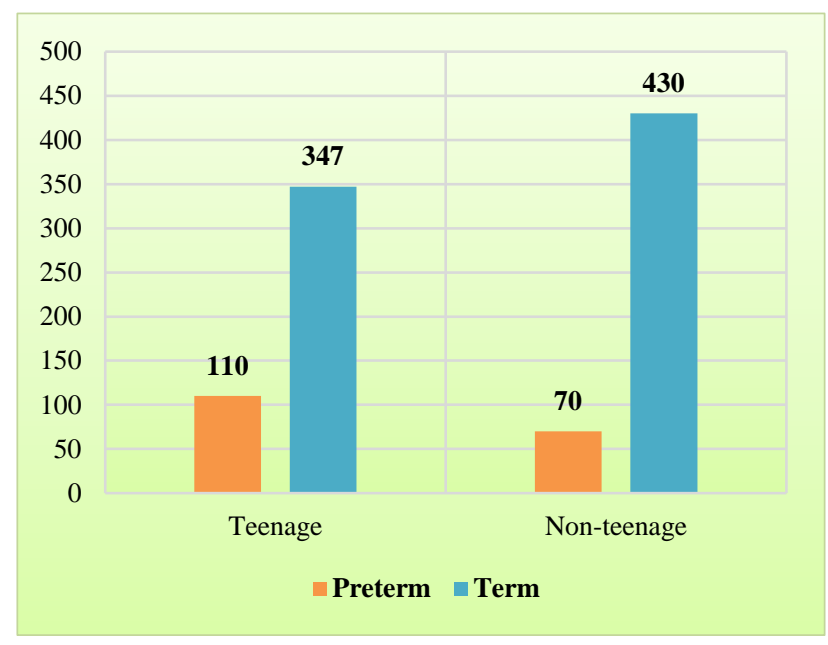

Figure 3: Preterm deliveries among teenage and nonteenage groups.

$112(24 \%)$ teenage mothers and 50(10\%) of non-teenage mothers had low birth weight babies and p value $(<0.05)$ was found to be statistically significant (Figure 4 ).

Hypertensive disorders in teenage pregnancies were comparable to that of non-teenage mothers. $39(8.6 \%)$ teenagers and $42(8.3 \%)$ non-teenagers developed preeclampsia. These results suggest that there was no statistical difference in preeclampsia among the groups (Figure 5).

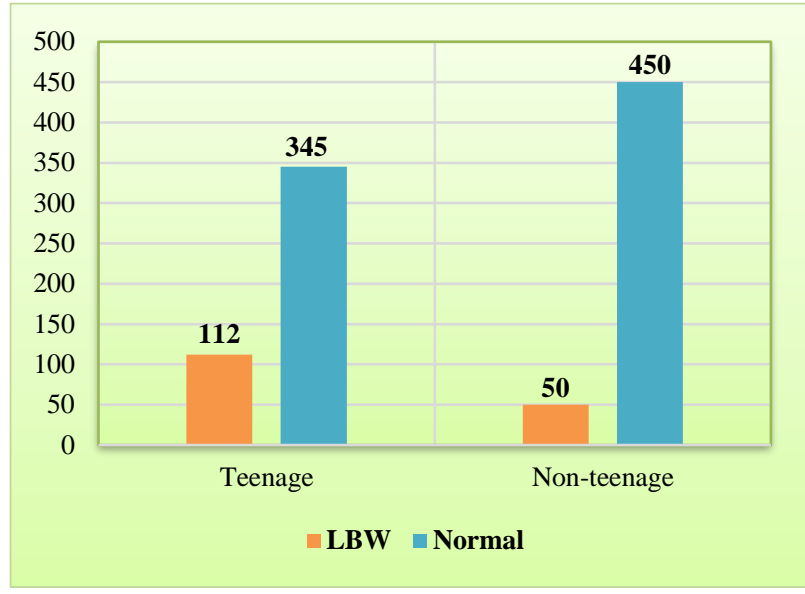

Figure 4: Low birth weight among teenage and nonteenage groups.

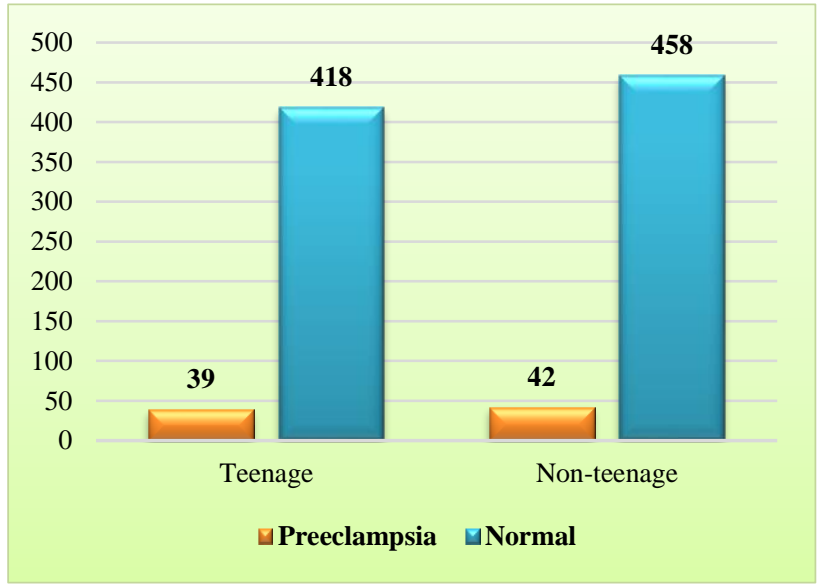

Figure 5: Preeclampsia among teenage and nonteenage groups.

\section{DISCUSSION}

The incidence of teenage pregnancy in the study period was $7.8 \%$. Incidence of teenage pregnancies was in the range of $4-10 \%$ in majority of the studies. ${ }^{6-11}$ In the study conducted by A Kumar and colleagues, the incidence of teenage deliveries in hospital was $4.1 \%$ and majority of the teenagers were primigravida 6 . In the present study, $39(8.6 \%)$ teenagers and $42(8.3 \%)$ non-teenagers developed preeclampsia suggesting that there was no statistical difference in preeclampsia among the case and control groups where as complications like pregnancy induced hypertension (PIH) $(11.4 \%$ vs $2.2 \%, \mathrm{p}<0.01)$, pre-eclamptic toxemia (PET) $(4.3 \%$ vs $0.6 \%, \mathrm{p}<0.01)$ and eclampsia $(4.9 \%$ vs $0.6 \%, \mathrm{p}<0.01)$ occurred more commonly in teenagers compared to controls in studies conducted by Kumar et al and they concluded that teenage pregnancy was associated with a significantly higher risk of PIH, PET, eclampsia, premature onset of labor, fetal deaths and premature delivery. Increased 
neonatal morbidity and mortality were also seen in babies delivered to teenage mothers. Younger teenager group
(17 years) was most vulnerable to adverse obstetric and neonatal outcomes. ${ }^{6}$

Table 3: Various studies on teenage pregnancy outcomes.

\begin{tabular}{|c|c|c|c|c|c|c|}
\hline STUDY & Type & $\begin{array}{l}\% \\
\text { teenage }\end{array}$ & Preterm & $\begin{array}{l}\text { Cesarean } \\
\text { delivery }\end{array}$ & Preeclampsia & $\begin{array}{l}\text { Low birth } \\
\text { weight }\end{array}$ \\
\hline Kumar A et al & $\begin{array}{l}\text { Retrospective } \\
\text { case-control }\end{array}$ & $4.1 \%$ & 26 vs $14 \%$ & $32 \%$ vs $38 \%$ & 11.4 vs $2.2 \%$ & $50 \%$ vs $32 \%$ \\
\hline Yasmin $\mathrm{G}$ et al & Prospective, & $5.1 \%$ & $16 \%$ & $11.6 \%$ & $20.2 \%$ & $16.9 \%$ \\
\hline Thaker R et al & $\begin{array}{l}\text { Retrospective, } \\
\text { observational }\end{array}$ & $5.1 \%$ & $17.8 \%$ & $31 \%$ & $9.8 \%$ & $46 \%$ \\
\hline Talawar S et al. & $\begin{array}{l}\text { Prospective, } \\
\text { case-control }\end{array}$ & $10.4 \%$ & $14 \%$ vs $2 \%$ & $21 \%$ vs $16 \%$ & $32 \%$ vs $13 \%$ & $27 \%$ vs $16 \%$ \\
\hline Chen XK et al & $\begin{array}{l}\text { Retrospective, } \\
\text { cohort }\end{array}$ & $8.75 \%$ & & & & $8.28 \%$ vs $6.26 \%$ \\
\hline Mukhopadhyay P et al & $\begin{array}{l}\text { Prospective, } \\
\text { Cross- } \\
\text { sectional }\end{array}$ & & $27 \%$ vs $13 \%$ & $28 \%$ vs $37 \%$ & & $39 \%$ vs $30 \%$ \\
\hline Present & $\begin{array}{l}\text { Retrospective } \\
\text { case-control }\end{array}$ & $7.8 \%$ & $24 \%$ vs $14 \%$ & $56 \%$ vs $42 \%$ & $8.6 \%$ vs $8.3 \%$ & $24 \%$ vs $10 \%$ \\
\hline
\end{tabular}

Preterm delivery among teenage group was $24 \%$ and among non-teenagers was $14 \%$ comparable to the study conducted by Yasmin and colleagues with the incidence of Preterm labour $27.45 \% .^{7}$ In a study conducted by Rajal Thaker et al, (17.8\%) of teenage mothers had preterm vaginal delivery. Most of these studies concluded that severe anemia in teenage mothers can lead to preterm labour, low birth weight, post-partum haemorrhage and sepsis in addition to impaired physical and cognitive development and increased risk of morbidity in children. ${ }^{6-10}$

$44 \%$ of teenage mothers had a normal vaginal delivery and $(58 \%)$ of non-teenage women had delivered vaginally. Rate of cesarean delivery among teenagers in the present study is $56 \%$ and among non-teenagers was $42 \%$.

The cesarean rates were higher in the study group. Most common indication for cesarean in the study group was Cephalopelvic disproportion followed by fetal distress Different studies in India reported cesarean rates among teenagers ranging between $12-32 \%$ (Table 2). 6,7,8,9 Regarding the mode of delivery, incidence of cesarean section were similar in both groups in a study conducted by Soubhagya Talawar and coworkers. ${ }^{9}$

Low birth weight in the present study among the teenagers was $24 \%$ and among non-teenagers was $10 \%$. In a study conducted by Agarwal $\mathrm{N}$ and Reddaiah VP, low birth weight babies were born more to the mothers with age below 20 years $(30.8 \%)$ as compared, to women more than 20 years of age $(25.3 \%)$. They concluded that prevalence of low birth weight was significantly associated with the mother's age. ${ }^{3}$

The primary limitation of the study was that, since it was conducted in a tertiary-care hospital set-up, chances of high-risk cases may be more, and it may not truly reflect the prevailing situation in a community setting. Sociodemographic characteristics like income, education could not be included in the study.

\section{CONCLUSION}

The adverse outcomes of teenage pregnancy could be attributed not only to lower maternal age but also to their relatively disadvantaged socioeconomic background. Health care system should aim to reduce the incidence of teenage pregnancy, not only to minimize the adverse outcomes on young mothers but also to limit the familysize.

Efforts need to be directed towards strict enforcement of laws prohibiting teenage marriage in India. For pregnant adolescents attending the antenatal clinic, extra care should be taken to ensure that the minimum number of regular antenatal visits is made. Contraceptive practices need to be promoted among adolescents to reduce pregnancy and childbirth at a very young age.

Teenage pregnancy needs to be tackled as a priority to ease the burden of socioeconomic and health problems.

\section{Funding: No funding sources}

Conflict of interest: None declared 
Ethical approval: The study was approved by the Institutional Ethics Committee

\section{REFERENCES}

1. International Institute for Population, Sciences (IIPS) and Macro International. 2007. National Family Health Survey (NFHS-3), 2005-06.

2. World Health Organization; Adolescent pregnancy September 2014. Available at http://www.who.int/mediacentre/factsheets/fs364/en/

3. Agarwal N, Reddaiah VP. Factors affecting birthweight in a suburban community. A study in a secondary level hospital in Delhi. Health Popul Persp. 2005;28(4):189-96.

4. Bott S, Jejeebhoy J. S. World Health Organization. Towards adulthood: Exploring the sexual and reproductive health of adolescents in South Asia. Geneva:2003:10

5. World Health Organisation. Programming for adolescent health and development. WHO Technical Report series. 1999;886:1-217.

6. Kumar A, Singh T, Basu S, Pandey S, Bhargava V. Outcome of teenage pregnancy. Indian $\mathrm{J}$ Pediatr 2007;74(10):927-31.
7. Yasmin G, Kumar A, Parihar B. Teenage PregnancyIts Impact on Maternal and Fetal Outcome. Int J Scien St. 2014;1(6):9-13.

8. Thaker RV, Panchal MV, Vyas RC, Shah SR, Shah PT, Deliwala KJ. Study of feto-maternal outcome of teenage pregnancy at tertiary care hospital. GMJ 2013;68(2):100-3.

9. Talawar S, Venketesh G. Outcome of Teenage Pregnancy. IOSR-JDMS. 2013;6(6):81-3.

10. Chen X K, Wen SW, Fleming N, Demissie K, Rhoads GG, Walker M. Teenage pregnancy and adverse birth outcomes: a large population based retrospective cohort study. Int J Epidemiol. 2007 ;36(2):368-73.

11. Mukhopadhyay P, Chaudhuri R.N, Paul B. Hospitalbased Perinatal Outcomes and Complications in Teenage Pregnancy in India. J Health Popul Nutr. 2010;28(5):494-500.

Cite this article as: Emani A, Shetty SK. Fetal Obstetric outcome of teenage pregnancies in a tertiary care centre in Mangalore, Karnataka, India. Int J Reprod Contracept Obstet Gynecol 2018;7: 1786-90. 